\author{
Georgiane Garabely Heil Vázquez
}

Universidade Estadual de Ponta Grossa, Ponta Grossa, PR, Brasil

\title{
Imperfeições no papel: a infertilidade nas páginas da Revista Pais \& Filhos
}

Resumo: Esta pesquisa teve por objetivo problematizar, a partir de uma dimensão histórica, a esterilidade/infertilidade na segunda metade do século XX no Brasil, segundo a análise documental da Revista Pais \& Filhos. Os temas centrais debatidos foram as narrativas construídas pela revista em torno da dificuldade ou impossibilidade de se ter um filho. O interesse versou sobre a articulação entre os saberes médicos e os discursos apresentados na Pais \& Filhos, quando a temática da infertilidade foi abordada. Foram usadas como bases teóricas as reflexões de Butler (2000; 2002), Braidotti (2001), Haraway, Kunzru e Tadeu (2000), dentre outras. Em linhas gerais, pode-se observar que a revista construiu estratégias narrativas que tornavam as mulheres inférteis em doentes. A gestação e o exercício da maternidade foram amplamente valorizados pela revista.

Palavras-chave: Infertilidade; maternidade; gênero; Revista Pais \& Filhos

\section{Notas preliminares}

[...] Uma mulher sã e madura tem boa relação com o marido e a família. Existem, no entanto, aquelas que são enfermas e as emocionalmente imaturas. Essas não podem assumir o papel que qualquer mulher normal desempenha na lógica da natureza (REVISTA PAIS \& FILHOS, n. 7, p. 40, mar. 1976).

Maternidade, natureza, felicidade. Palavras inundadas de significações simbólicas e sociopolíticas, amplamente usadas para compor um ideal de vida e reforçar discursos que legitimam estigmas referentes às mulheres que não se tornaram mães. Ao se problematizar sobre a experiência de ausência da maternidade, percebe-se que a intimidade, o corpo e a reprodução humana ganham espaços em diversos segmentos sociais, dentre eles, a mídia escrita.

\section{(c) (i)}

Esta obra está sob licença Creative Commons. 
Neste artigo busca-se analisar as publicações da Revista Pais \& Filhos no que tange ao tema da infertilidade, seja ela masculina ou feminina. O recorte cronológico escolhido para a análise vai de 1968, ano de início das atividades editoriais da Pais \& Filhos, até o ano 2000, data escolhida como marco por se tratar do fim do século XX; século este que ficou consagrado como sendo o período de maior valorização da maternidade e da criança. Foi o século da suposta consolidação do saber médico sobre a maternidade e das pesquisas e descobertas na área da fertilização humana.

As revistas usadas para este artigo encontram-se disponíveis no setor de periódicos da Biblioteca Pública do Paraná. Foram verificados um total de 384 revistas e selecionados 134 artigos, em diferentes seções da revista, que abordam temas vinculados a abortos, infertilidade, comportamentos adequados às mães, idade feminina ideal para engravidar, amor materno, entre outros. Em se tratando do tema escolhido para análise neste artigo, a infertilidade, cabe observar que respondem por 24 artigos daquele total de 134 já mencionados.

A revista, como toda e qualquer documentação, é 'inundada' por diversos discursos. Aqui, no caso específico, observam-se os discursos sobre maternidade e ausência dela, sendo que na documentação pesquisada o discurso médico/clínico se sobressai mas, junto a ele, se encontram também o discurso psicológico, o pedagógico e, evidentemente, o jornalístico. Ressalta-se que, conforme lembra Margareth RAGO (2009), o discurso não é uma imposição de ideias, pois os indivíduos são formados nos discursos e o aceitam em maior ou menor grau, desta forma, o discurso constrói a visão de mundo, ou seja, constrói parte da própria subjetividade do indivíduo.

Com isso não se pretende afirmar que existe uma única normatização geral para o corpo social, incluindo aí o desejo de ser mãe, mas sim que não existe objeto pré-discursivo e, desse modo, o desejo de maternidade foi formulado por diversos discursos e é constantemente reforçado por argumentos discursivos. Portanto, é necessária a elaboração de novos e diferentes discursos para que existam novas e diferentes formas de existir e viver a experiência de maternidade e também de ausência dela (RAGO, 2009).

Desta forma, compreende-se que existem em nossas sociedades diferentes mecanismos que transformam o corpo, e um destes mecanismos é o discurso. Ao se construir um discurso sobre a materialidade dos corpos, ou seja, sobre o corpo biológico, inicia-se um processo sofisticado e sutil de elaboração de ideais e práticas para esses corpos. Ao corpo biológico tais mecanismos sociais iniciam um processo de atribuição de gênero e, neste sentido, ao corpo feminino a maternidade é cuidadosamente elaborada como uma das principais maneiras para atingir a felicidade e até como fonte de equilíbrio (Magali ENGEL, 1997). Assim, por exemplo, ao nascer biologicamente com um aparelho genital feminino, a mulher é exposta e, muitas vezes, até convencida de que deve agir de determinada maneira em virtude de seu órgão sexual e reprodutivo (Judith BUTLER, 2002).

É neste sentido que é feita a materialização dos corpos, pois a partir das atribuições e papéis sociais dados para cada corpo é que paulatinamente vão se formando os sujeitos sociais. Os corpos pesam porque é por meio desta articulada engrenagem de "moldura de mulheres" que boa parte da sociedade acaba por dar uma identidade social aos corpos femininos e é por meio desta identidade que alguns corpos são socialmente aceitos, enquanto outros são marginais, corpos desviantes e, especificamente no caso que trata este artigo, corpos classificados pelo discurso médico como sendo patológicos, pois são corpos femininos mais não conseguem gestar um bebê (BUTLER, 2002).

Desde meados do século XIX ocorreu a consolidação de uma rede de saberes e práticas médicas que, tomadas como verdades, foram se propagando por diversos segmentos sociais e paulatinamente modificando os costumes e construindo novas formas 
de entender o corpo e a maternidade. O desejo de conhecimento médico sobre o corpo feminino, articulado à função reprodutiva, se acentua nos oitocentos com a consolidação da ginecologia e da obstetrícia. Todavia, ainda no início do século XX, se tratava de saberes que eram divulgados para um público específico, os próprios médicos (Ana Paula Vosne MARTINS, 2000, p. 113-116).

No Brasil, foi somente a partir do início da circulação da Revista Pais \& Filhos, em setembro de 1968, que tais saberes médicos/clínicos ganharam espaços de circulação social mais ampliado. Sendo um órgão midiático de grande circulação, vendida também em lojas de livros e revistas usadas por preços mais acessíveis, tal revista se tornou um importante veículo de divulgação sobre as 'tarefas maternas', assim como um guia de informações para encontrar a solução de problemas e até uma espécie de modelo, no estilo "faça você mesmo", sendo compreendida aqui como um veículo de intermediação entre o saber médico e as mulheres.

Analisar as engrenagens discursivas da Revista Pais \& Filhos e suas "verdades" sobre os corpos inférteis é o que doravante pretende-se fazer.

\section{A Revista Pais \& Filhos e os discursos sobre a cura da infertilidade}

Passa-se, agora, a analisar alguns dos textos publicados sobre a infertilidade na Revista Pais \& Filhos, seja infertilidade masculina ou feminina, embora seja necessário mencionar que a infertilidade feminina é amplamente mais debatida na revista do que a masculina.

Ao tratar da gestação, da lactação e, nos textos aqui debatidos, da infertilidade, a revista apresenta uma série de normatizações para a maternidade. Nesse sentido, promove, ao longo da segunda metade do século XX, o processo que Maria Simone SCHWENGBER (2007) chamou de "redescobrimento dos corpos". Esse processo se deu em articulação com os saberes e discursos médicos, tendo em vista a ampla participação dos médicos, seja prestando consultoria para as matérias, seja como autores de artigos propriamente ditos. A forma de engendramento de saberes médicos foi altamente sofisticada, pois vinculou os conceitos e as normas sobre o "cuidado de si" desenvolvidas pelos médicos com um novo discurso, o jornalístico (SCHWENGBER, 2007, p. 123-138).

Assim, a revista pode ser entendida como uma espécie de "ponte" entre o conhecimento médico e as mulheres. Estas não são mais vistas como receptáculos de um saber/poder, mas percebidas como agentes de seus próprios corpos. Por meio da divulgação dos conhecimentos pela revista, cada mulher em potencial poderia dispor de seu corpo para corrigir imperfeições e desvios, embora guiada pelo saber enunciado na revista.

Segundo Schwengber (2006), a Revista Pais \& Filhos, desde seu início, difundiu a ideia de que o sujeito é seu próprio corpo. Assim, um corpo imperfeito para a maternidade era facilmente classificado como um corpo inferior, portanto, deveria sujeitar-se aos saberes difundidos na revista e procurar auxílio para corrigir seu "defeito natural". Para a autora, a reprodução humana passou a ser tratada amplamente nas páginas da Pais \& Filhos como assunto político e, para colocar em prática essa nova rede de conhecimento e normatização sobre os corpos, se formou uma significativa rede de propagação de saberes científicos. Saberes, porém, de fácil acesso e com informações complementares que levavam aos endereços de consultórios médicos especializados em reprodução humana (SCHWENGBER, 2006).

Dessa forma, é necessário compreender que a Revista Pais \& Filhos, com seu discurso de valorização da maternidade e apresentação de múltiplos caminhos para a "cura" da 
infertilidade, não visava, em última instância, à normatização ou padronização geral das mulheres, mas sim se apresentava como um veículo de enunciação de discursos que, na maioria das vezes, refletiam simplesmente o senso comum sobre a ideia de felicidade plena feminina vinculada à maternidade. Neste ponto, percebe-se que não existe uma separação estanque entre o que se classifica como discurso médico e o discurso social. As verdades propostas pelos saberes médicos são, em última instância, verdades socialmente construídas e, portanto, existe uma constante interação entre esses campos discursivos, sendo que a Revista Pais \& Filhos é um bom exemplo de como essa dinâmica de intermediação funcionou.

Ao abordar a possibilidade de recurso médico em caso de dificuldades para engravidar, a Revista Pais \& Filhos publicou a seguinte reportagem: "Doutor, posso ser MÃE?", de maio de 1972.

A apresentação do artigo traz um grande olho feminino mirando o vulto de uma criança correndo e, em negrito, ainda na mesma abertura, traz as seguintes palavras:

É possível que este seja o seu caso: casada, feliz, aparentemente saudável, mas sem ter tido ainda a alegria de uma gravidez. Nos primeiros tempos, você não levou a coisa muito a sério, mas com o passar dos meses, começou a ficar preocupada. Quase em pânico. Começou a sonhar com bebê, brinquedos, caminhas, mamadeiras. Começou a ficar com medo de jamais ser chamada de mamãe, apesar de todos os esforços (REVISTA PAIS \& FILHOS, 1972).

É possível perceber, pela abertura da reportagem, que o ideal de felicidade feminina estava estritamente vinculado à maternidade, e a infertilidade ou a esterilidade seriam males que deveriam ser combatidos a todo custo (incluindo custo financeiro). Todavia, na mesma reportagem, a revista menciona:

O ter filhos não é mais hoje encarado, como já foi em outros tempos, como a única função da mulher neste mundo. E da mesma forma que um casal vive bem e se ama com filhos, pode também viver bem e se amar sem filhos (REVISTA PAIS \& FILHOS, 1972).

A visão da revista a respeito da mulher e da fertilidade apresenta algumas sutilezas. Tania Regina de LUCA (2005) nos lembra que a própria materialidade da fonte deve ser observada. Nesse caso, pode-se ver que afirmações voltadas para o ideal de maternidade e realização feminina são ressaltadas de inúmeras formas. No título do artigo, a palavra mãe aparece em destaque, com letras em caixa alta, enquanto a imagem de capa apresenta o olhar desejoso de uma mulher em ter uma criança e, ainda no início da reportagem, as frases de chamada para o artigo relacionam explicitamente a ideia de realização feminina com a maternidade.

No mesmo artigo, há o depoimento de uma jovem de 26 anos que afirmou não ter tido maiores problemas ao lidar com suas dificuldades para engravidar, "[...] mas que só agora, depois de ser mãe se sente realizada, se sente uma mulher completa" (REVISTA PAIS \& FILHOS, 1972). E como título para esse depoimento que narra uma verdadeira maratona de exames e tratamentos médicos para ter um filho, encontramos a seguinte frase: "Eles venceram a esterilidade".

Em contrapartida, a passagem que afirma outras possibilidades de realizações que extrapolam a obrigação de maternidade se encontra no meio de parágrafos que valorizam a maternidade, ou seja, seria como uma forma de consolo que a revista oferecia para aquelas "pobres coitadas" que não conseguem exercer o "dom sublime" da maternidade.

Ao se comparar os espaços destinados na revista para os trechos mencionados acima, chama-se a atenção para o fato de que a materialidade dos impressos e seus 
suportes não se dão ao acaso. O uso de determinada letra, maiúscula ou minúscula, o que foi colocado em negrito ou o que está em formato diferenciado, tudo isso tem um significado e demonstra a intenção de destacar/reforçar um determinado discurso. Ao fazer isso, buscase historicizar não só o tema em questão, mas também a documentação e, com isso, ter em conta as condições técnicas de sua produção, atentando principalmente para o que foi escolhido para ser colocado em destaque e o porquê de tal ênfase.

Nesse sentido, observa-se que existe significativa diferença entre as reportagens de infertilidade/esterilidade feminina e masculina. Via de regra, as reportagens que tratam de questões relacionadas ao organismo das mulheres apresentam imagens de crianças, fotos de mulheres com o olhar voltado para o horizonte, como se estivessem refletindo, além de desenhos de partes do corpo, como úteros e ovários, e até uma reportagem com a foto de um belo e enfeitado berço, porém vazio, sem nenhum bebê. Em contrapartida, as poucas reportagens encontradas sobre a infertilidade/esterilidade masculina não estão associadas às imagens de crianças ou berços. As capas e páginas das reportagens que tratam das complicações masculinas trazem apenas palavras, ou seja, apenas os títulos das matérias, com pouca ou nenhuma foto. Em duas reportagens, encontramos fotos: uma de 1977, em que aparece uma foto de homem com uma calça jeans justa e sensual, centrada na região da genitália; em outra, do ano de 1986, em que aparece um corpo masculino de costas e nu, também fotografado com sensualidade.

Ao analisar mais detalhadamente as reportagens, foi possível observar que até a linguagem utilizada era diferente. Esse é o caso da reportagem de março de 1977, em que a Revista Pais \& Filhos tratou do tema "vasectomia". Diferente das demais reportagens selecionadas para se analisar a infertilidade, nesta matéria ocorreu uma "opção" pela esterilização. O título da reportagem era "Vasectomia: a esterilidade ao alcance do homem". Em uma abordagem rápida, a matéria de apenas uma página procurava explicar que a operação em questão era rápida e indolor. Mas o fato que chamou atenção nessas informações foi a necessidade que a revista apresentou de diferenciar esterilidade com potência sexual:

Nos casos em que a mulher fica impedida de ter filhos, o médico comunica à cliente o seu estado e aí surge a hipótese da esterilização do homem. O que não é fácil. Quando ela é feita, quase sempre é mantida em segredo, pois na nossa sociedade a potência do homem reside no fato de ter filhos. E um homem estéril é quase considerado um impotente (REVISTA PAIS \& FILHOS, 1977).

Nesse discurso apresentado pela revista, pode-se observar que, quando a infertilidade ou a esterilidade feminina eram o tema, não havia, em nenhum momento, vinculação com o desejo sexual. Em contrapartida, todas as vezes em que a infertilidade masculina foi tratada, houve, em todos os períodos, a menção à potência sexual. Nesse sentido, a revista procurava deixar claro que o fato de um homem optar pela esterilidade (fazendo a vasectomia) ou possuir alguma limitação para engravidar uma mulher não significava de forma alguma que esse homem não era viril, podendo, mesmo com a limitação vinculada à reprodução, ser um ótimo parceiro sexual e para a vida.

Nem de longe as reportagens sobre infertilidade feminina versavam sobre o desejo sexual, o que evidencia a dificuldade encontrada em desnaturalizar papéis socialmente construídos. Todavia, é necessário fazer essa 'desconstrução desnaturalizante' não como um simples desmontar ou destruir, mas sim como um repensar teoricamente a "identidade construída".

Se a ideia de que os binarismos são necessários for aceita, acaba-se por não problematizar o fato de que, por ter nascido mulher, a maternidade estaria no seu destino, 
como se existisse um destino biológico. Dessa forma, é preciso desnaturalizar a noção de sexo e também a de gênero, pois, do contrário, pode-se concordar com o fato de que as mulheres, sendo portadoras de um aparelho reprodutor complexo, estariam todas biológica e culturalmente destinadas à maternidade e à infelicidade caso tivessem problemas para engravidar.

Ao longo das vinte e quatro reportagens sobre infertilidade, não observamos qualquer questionamento da revista nesse sentido, porém, como bem demonstrou Butler (2000), a própria noção de gênero e tudo o que circunda tal conceito não é natural. O gênero, assim como a noção de sexo, foi discursivamente construído.

Quando a revista, por meio de suas reportagens sobre infertilidade, estabelece uma diferenciação binária, construindo a ideia de que os homens - mesmo estéreis - são viris e, em outro extremo, a ideia de que mulheres inférteis precisam de ajuda psicológica e médica para alcançar a cura para poderem sentirem-se "completas", está, na verdade, reforçando - ou até recriando - "o mito do natural". As novas tecnologias reprodutivas são usadas para recriar com maior legitimidade o mito do natural, e isso acaba por reforçar uma visão binária sobre a sexualidade e a reprodução humana. Dentro dessa lógica conservadora, mulheres "completas" devem submeter o corpo e a mente às práticas de maternagem, enquanto o mesmo não é "cobrado" dos homens na mesma proporção (Marlene TAMANINI, 2003).

A primeira reportagem da Revista Pais \& Filhos que tratou da infertilidade masculina é datada de fevereiro de 1969, ou seja, a revista ainda estava com poucos meses de circulação. Com o título "Homem também é estéril", a revista dedica três páginas para tratar "do casal". É de singular importância tal fato, pois quando trataram de questões relacionadas ao corpo feminino, as reportagens giravam em torno da "infertilidade feminina". Todavia, quando o homem aparece na cena dos discursos sobre infertilidade, cria-se o conceito de "casal infértil". A reportagem inicia, então, da seguinte maneira:

Se é verdade que a mulher continua a falar do marido estéril como se êle nunca tivesse existido - embora no íntimo encare o fato com uma certa dúvida e até com um sentimento de frustração, a verdade também é que as últimas estatísticas afirmam que, em 1000 casos de esterilidade do casal, o homem tem de 30 a 50 por cento de responsabilidade. Pode acontecer que êle, como doador de sêmen, não esteja em condições de cumprir sua parte na fecundação. [...] O problema é que, na maioria das vezes, o homem não sabe que é estéril, porque, em geral, êle goza de boa saúde, tem aspecto saudável e não há qualquer dúvida quanto ao seu comportamento sexual (REVISTA PAIS \& FILHOS, 1969, p. 28).

A reportagem segue informando sobre as questões médicas/clínicas que podem dificultar a fertilidade e que são provocadas por pouca resistência, ou mesmo pouco líquido espermático. Ainda é apresentada uma série de questões nutricionais que poderia afetar o organismo masculino e gerar a infertilidade, contudo, é no final da reportagem que fica evidente a articulação de fecundidade e potência para os casos masculinos. A revista descreve uma situação de consulta médica e afirma que tal história sintetizaria tudo o que envolve a infertilidade masculina:

Uma mulher chegou à Clínica de Fertilidade e contou ao médico que estava casada há quatro anos, sem conseguir filhos. Fôra várias vezes ao ginecologista, havia se submetido a todos os exames e acabara convencida de que seria capaz de conceber. Perguntou ao especialista se tinha o direito de pensar que a culpa cabia ao marido e, se isso fosse verdade, como convencê-lo a fazer uma consulta, porque, apesar de ser um homem de certa cultura, dava muito valor a sua virilidade. O médico aconselhou-a a não 
superestimular [sic] o orgulho do companheiro. Deveria tentar persuadi-lo a aceitar o fato com tranquilidade e a sujeitar-se as pesquisas necessárias, sem ficar ofendido na sua integridade masculina. Também propôs à mulher que deixasse de lado as incertezas e pudores e dissesse ao marido que, ao submeter-se aos exames, êle estaria dando provas de maturidade, estima e respeito mútuo. Em todo caso, se não obtivesse êxito, então seria melhor convidá-lo a uma simples conversa com o médico [...]. Um mês mais tarde a consulta foi marcada e, após alguma resistência, iniciados os exames [...]. O exame de urina revelou que havia piúria maciça, isto é, emissão de urina purulenta. $E$ num estudo completo ficou provado que o paciente tinha tuberculose renal. Descoberta a causa da esterilidade ${ }^{1}$ e fixado o tratamento, êle agora caminha para a cura completa (REVISTA PAIS \& FILHOS, 1969, p. 30).

Outro ponto que merece ser destacado ao se analisar as reportagens sobre infertilidade é a extrema valorização das tecnologias reprodutivas. Novamente, pesa sobre os corpos o discurso ligado à necessidade de submetê-los à maternidade, não importando o quanto isso custe em termos financeiros ou mesmo emocionais. Um exemplo disso foi a reportagem de setembro de 1978, intitulada "Cada vez mais casos de esterilidade têm um final feliz". A matéria em questão trata do nascimento de Louise, o primeiro bebê de proveta do mundo, nascida na Inglaterra em 25 de julho de 1978. A reportagem afirma:

A notícia é do conhecimento de todos. Louise, o bebê resultante de fecundação em um tubo de ensaio, já é personalidade mundial. Representa a esperança na maternidade, embora ainda longínqua para mulheres que tenham problemas de obstrução de trompas, um dos fatores de esterilidade. $O$ fato do sucesso da façanha científica dos dois médicos ingleses poderia ser paradoxal num mundo em que se torna prioritária a questão da superpopulação, vaticinada nas próximas décadas. Mas a tecnologia é a musa do nosso tempo. Ademais, esse acontecimento científico vem de [sic] encontro a uma das inquietações do homem - perpetuar-se através da espécie ${ }^{2}$ (REVISTA PAIS \& FILHOS, 1978, p. 108).

Essa extrema valorização da tecnologia, de forma geral e, aqui especificamente, da tecnologia reprodutiva, chamando-a inclusive de "musa de nossos tempos", possibilita a reflexão sobre os limites, ou a ausência deles, sobre a submissão dos corpos ao poder médico/clínico. Assim, por meio da medicina dos tempos modernos, foram se construindo novos ciborgues, onde se estabelece a junção entre o organismo e a máquina, cada qual concebido como um dispositivo codificado com intimidade e poder sobre a sexualidade e os corpos, antes "apenas" humanos. A partir dessa nova situação de ciborgues, Donna HARAWAY, Hari KUNZRU e Tomaz TADEU (2000) demonstram que o próprio conceito de biopolítica, desenvolvido por Foucault, apresenta limites diante de um campo muito mais aberto, pois, na segunda metade do século $X X$, somos todos quimeras, híbridos, ou seja, misturas de tecnologias com organismos (HARAWAY; KUNZRU; TADEU, 2000).

Possuímos, portanto, uma nova ontologia, uma ontologia ciborgue e, com isso, natureza e cultura são reestruturadas: uma não podendo mais ser objeto de apropriação ou de incorporação pela outra (HARAWAY; KUNZRU; TADEU, 2000, p. 40-41).

\footnotetext{
${ }^{1}$ A revista faz maior distinção entre esterilidade e infertilidade nos anos de 1990. Atualmente, sabe-se que a infertilidade pode ser tratada e a esterilidade não, necessitando de doador de material genético. Nesse caso, apresentado em 1969, tratava-se de infertilidade, embora a revista tenha denominado como um caso de esterilidade.

${ }^{2}$ Registra-se o erro de redação da revista "[...] Vem de encontro [...]" quando na forma culta da língua portuguesa deveria ser "vem ao encontro". Equívoco que, no caso, modifica o sentido pretendido à frase. Todavia, dentro das concepções e metodologias da História às quais me alinho, o(a) pesquisador(a) mantém a forma original de redação da documentação.
} 
A perspectiva analítica e conceitual anticonservadora de Haraway, Kunzru e Tadeu (2000) é oposta aos conceitos apresentados pela Revista Pais \& Filhos. A revista vê na tecnologia reprodutiva um caminho viável para a recriação do mito do natural, com os papéis sexuais claramente determinados e dentro de fronteiras discursivas muito bem traçadas. Ao apresentar o ciborgue como o humano atual, Haraway, Kunzru e Tadeu (2000) revelam o poder que a medicina e as técnicas biomédicas em geral têm sobre os corpos, mas a essência de sua proposta é libertadora. Nesse sentido, a autora afirma que o ciborgue é uma criatura de um mundo pós-gênero, e que, portanto, não tem qualquer fascínio por uma totalidade orgânica. O ciborgue apresentado por Haraway, Kunzru e Tadeu (2000) não integra qualquer narrativa que faça apelo a um estado original ou a uma narrativa de origem.

Já o discurso apresentado na Revista Pais \& Filhos é, em certa medida, universalista, pois tenta fixar a categoria mulher e, mais estritamente, a "mulher-mãe-feliz". Haraway, Kunzru e Tadeu (2000), assim como Butler (2000; 2002), nos alertam para o fato de que as identidades são contraditórias, parciais e estratégicas. Partindo desse pressuposto, não existe nada no fato de ser "mulher" que naturalmente una as mulheres. Aliás, é necessário até mesmo romper definitivamente com a ideia de "ser mulher", pois é uma categoria complexa, construída por discursos morais, científicos e sexuais. Ao estabelecer tal desnaturalização da ideia de mulher, por extensão, precisa-se fazer o mesmo com o conceito de gênero. O gênero não pode ser uma identidade global (relação entre homens e mulheres - e estes como categorias tão bem definidas e delimitadas). Todavia, mesmo não se aceitando o gênero como identidade global, deve-se reconhecer sua intensa profundidade e amplitude nas relações humanas, haja vista a própria construção discursiva feita ainda no final do século XX pela Revista Pais \& Filhos e por tantos outros meios de comunicação que acabam por influenciar na construção de papéis sociais para homens e mulheres.

Por inúmeras vezes, ao longo das reportagens que tratam de infertilidade em tal revista, percebe-se a articulação da ideia de que o corpo, e em especial o corpo feminino, deve se sujeitar à tecnologia médico/clínica. Nesse sentido, é significativa a reportagem apresentada em 1973 com o título "Novas descobertas na cura da esterilidade", onde são mencionadas as mais variadas e modernas técnicas para se obter sucesso na fertilização humana. A matéria trata de um congresso médico ocorrido na Grécia, onde os mais renomados especialistas mundiais em infertilidade apresentaram seus estudos.

Dentre as inúmeras conquistas médicas contra a infertilidade, a revista optou por destacar a do médico Rezso Gimes, do Departamento de Ginecologia da Universidade de Budapeste. A descoberta de Gimes foi tratada com entusiasmo e classificada como a mais original no campo da inatividade ovariana. Trata-se de uma técnica para estimular a ovulação que consiste em

[...] obter a ovulação através de estímulos elétricos no colo do útero. Em todas as pacientes, depois de algumas sessões de estímulos elétricos de baixa freqüência, aplicados por um tempo variado entre 3 a 60 segundos, foi restabelecido o ciclo menstrual normal. Atualmente 9, das 16 mulheres que receberam os estímulos elétricos no útero, estão esperando um filho (REVISTA PAIS \& FILHOS, 1973, p. 18).

Tal declaração médica foi tratada com muito entusiasmo pela revista, e em nenhum momento a reportagem questionou se a mulher que recebia "estímulos elétricos" no útero poderia ter alguma sequela ou dano para sua saúde futuramente. Essa constatação vai ao encontro do que Schwengber (2006) constatou ao se debruçar sobre a análise da Revista Pais \& Filhos, ou seja, pelo menos até fins da década de 1970, o discurso médico era proeminente, definindo-se como um discurso que respondia de forma quase que absoluta pelo processo da gravidez e por sua ausência.

8 Revista Estudos Feministas, Florianópolis, 26(1): e44155 
Mesmo quando a palavra não era dada a um médico, mas sim ao repórter responsável pela matéria, pode-se observar que as novidades da medicina constituíam a única forma eficaz para a mulher conseguir ser mãe. Na reportagem "Esterilidade: um mal que pode ser inteiramente curado" percebe-se a interferência clínica na ausência de filhos. Dessa forma, a mulher necessita de "cura", e essa cura provinha dos saberes médicos. A foto de capa dessa reportagem apresenta uma bela mulher, bem maquiada e usando joias, mas seu olhar e seu semblante são de desapontamento e de frustração. Logo abaixo dessa imagem, vem o texto inicial da matéria:

Contente, a mulher decide ter um filho. Os métodos anticoncepcionais são suspensos e toda a família vive a expectativa de vinda do herdeiro tão desejado. O tempo passa, e com ele a certeza de que 'ainda não foi desta vez'. Mais algumas tentativas e novas desilusões. Depois de muito sofrimento, ela acaba se conformando: 'Não adianta, eu não posso ser mãe'. Para evitar que este fato seja aceito como definitivo, vamos mostrar que a esterilidade pode ser combatida e curada. Ao invés de cair no desânimo é só procurar um especialista quando surgem as primeiras suspeitas (REVISTA PAIS \& FILHOS, 1973, p. 47).

Fica evidente que a revista se articula como uma espécie de porta-voz de um saber médico. Assim, se estabelece uma nova relação com a sexualidade, o corpo e os poderes exercidos sobre ele, pois ao contrário de um poder centralizador que governa e normatiza corpos, a revista propõe uma nova dinâmica, onde os saberes médicos são disseminados para um público relativamente amplo, e as descobertas vinculadas à cura da infertilidade apresentadas nos mais recentes congressos de medicina ocorridos no mundo são acessíveis a todas as leitoras da revista, possibilitando, assim, que elas procurem seus médicos e os questionem sobre as técnicas, os estudos e as práticas inovadoras que as podem auxiliar no combate à infertilidade.

Em julho de 1985, a revista propôs um debate entre seus colaboradores/repórteres e um médico, Elsimar Coutinho, então professor de Reprodução Humana da Universidade da Bahia e especialista em infertilidade. Coutinho foi alvo das críticas de segmentos do movimento feminista brasileiro devido à forma como entendia questões relacionadas à procriação e à esterilização de mulheres. Todavia, no meio acadêmico da década de 1980, o médico era visto como autoridade inquestionável nos assuntos relacionados à fecundação humana e à infertilidade, e, dessa forma, foi convidado pela Revista Pais \& Filhos para travar um debate com seus jornalistas sobre as dificuldades em engravidar e manter a gestação. Essa prática de debate foi justificada pela revista devido ao grande número de cartas que chegavam à redação contando histórias de casais que tentavam, sem sucesso, ter filhos. Dessa forma, a revista, baseada nas cartas das "leitoras inférteis", elaborou uma série de perguntas ao referido especialista, que se comprometeu em responder com a maior exatidão possível.

O médico mencionou que a Organização Mundial de Saúde (OMS) vinha tentando mapear a extensão do problema da infertilidade, ou seja, descobrir qual o número aproximado de casais que possuíam dificuldades para engravidar e necessitavam de auxílio médico. As estimativas publicadas pela revista davam conta de que cerca de $10 \%$ dos casais possuíam tal dificuldade.

Quando o médico foi questionado pela reportagem sobre se, especificamente no Brasil, havia alguma pesquisa nesse sentido, ele respondeu que realizou na Bahia uma pesquisa com mil casais de diversas camadas sociais, mas com predominância de camadas financeiramente menos favorecidas, e obteve a estatística de $3 \%$ de infertilidade. 
Elsimar Coutinho mencionou ainda que pretendia realizar essa pesquisa em cidades chamadas por ele de mais ricas, como Rio de Janeiro e São Paulo, com o argumento de que o poder aquisitivo interfere na infertilidade, pois, segundo ele,

\begin{abstract}
minha impressão é de que a infertilidade é muito mais comum nas camadas de renda mais alta. O motivo é fácil de explicar: o ser humano descobriu maneiras de resolver o problema - até bebê de proveta a gente fez - mas elas são caras e nem todos possuem acesso a estas soluções. Nas camadas menos favorecidas, a mulher sofre, encerra a questão por falta de recursos para repará-la e não transmite para suas filhas uma herança de infertilidade, simplesmente porque ela não vai ter filhas. Isso resulta, sem dúvidas, em um número menor de casos (REVISTA PAIS \& FILHOS, 1985, p. 114).
\end{abstract}

Por essa fala, o médico constata e reafirma a influência da diferença de classes e a ideia de que os avanços médicos na área da reprodução humana não são para todos, mas somente para aqueles que dispõem de recursos financeiros para iniciar tal empreitada no campo da medicina reprodutiva. Quanto àquelas mulheres ou casais sem recursos, restava a resignação diante da natureza ou, então, a adoção. Ao ser questionado sobre as crianças abandonadas e o pouco incentivo dado pela sociedade à adoção, o médico comentou:

Trata-se de um direito e de um dever. Todos nós temos o direito de ter filhos e todos temos também o dever de limitá-los para atender a uma exigência da comunidade. Se você tiver muitos filhos, na certa não poderá cuidar deles e acabará jogando esta responsabilidade nas costas dos outros. Da mesma forma acho que todas as famílias têm o direito de ter o filho que querem e cabe a nós, médicos, ajudá-los a realizar este desejo (REVISTA PAIS \& FILHOS, 1985, p. 114).

A reportagem prossegue, e o médico é perguntado sobre a infertilidade masculina. Prontamente, responde sobre as inúmeras causas que podem gerar tal problema, indo desde varizes no saco escrotal até baixa produção de esperma ou mesmo doenças como a caxumba. Mas o que mais chamou atenção foi o fato de ele destacar que

[...] é bom lembrar ainda que a impotência e a falta de freqüência nas relações sexuais podem estar originando a infertilidade. Quando o homem tem relações espaçadas demais, os espermatozoides vão se acumulando em sua vesícula seminal, tornando-se com o passar dos dias envelhecidos e com pouca vitalidade para a tarefa heróica da fecundação (REVISTA PAIS \& FILHOS, 1985, p. 114).

Nesse ponto, o médico ressalta a importância de manter relações sexuais frequentes para o melhor desempenho da fertilidade masculina.

Durante o período aqui estudado (1968 a 2000), os médicos não chegaram a um acordo sobre o tempo que o casal precisa ficar tentando engravidar. Os números variam, mas em escala pequena. Alguns médicos consultados pela revista afirmam que, com oito meses de relações sexuais frequentes e sem anticoncepcionais, o casal que ainda não conseguiu engravidar poderia se considerar infértil e procurar ajuda. Outros especialistas sustentam que o prazo de tentativas deve ser de um ano; já outros apresentam o prazo de dez a doze meses, e alguns ainda optam pelo período de dois anos. Todavia, em um fator todos os especialistas consultados pela revista concordam: para ser considerado infértil, deve-se estar tentando a gestação há algum tempo, sem nenhum tipo de controle e com o mesmo parceiro sexual.

A questão de se estabelecer como critério para o diagnóstico de infertilidade a necessidade de que as tentativas de gestação sejam com o mesmo parceiro é explicada pelos médicos devido ao fato de que a quantidade de esperma expelida em uma ejaculação varia de homem para homem. Segundo a revista, quanto maior essa quantidade 
de espermatozoides, maior a facilidade desse homem engravidar uma mulher. Dessa forma, uma mulher que possui uma taxa de fertilidade baixa, mas em contato com um homem que possui uma taxa de fertilidade alta, terá maior chance de não enfrentar problemas para engravidar. No outro ponto, se a mulher que possui uma taxa de fertilidade baixa também estiver se relacionando com um homem que possua essa mesma característica, as chances de uma gestação sem ajuda médica serão praticamente nulas.

Com esse argumento apresentado diversas vezes ao longo das matérias referentes à infertilidade na revista, os médicos procuram incentivar a manutenção de relações sexuais vinculadas a um único parceiro para, então, se saber se existe algum problema de fertilidade.

Por meio da reportagem/entrevista com Elsimar Coutinho, assim como por outras várias passagens tratando de infertilidade e reprodução humana, verifica-se que as tecnologias de controle sobre si mesmo são corporizadas nos sujeitos, e estes entram em intersecção com as macroinstâncias que governam a produção de discursos socialmente reconhecidos como "verdadeiros" e cientificamente válidos. Contudo, não se afirma que as tecnologias do final do século XX, com destaque para as tecnologias de reprodução humana, são, a priori, algo que se oponha ou prejudique a humanidade. As tecnologias vêm ultimamente cumprindo com o "destino biológico" do ser humano de uma maneira tão íntima, que o orgânico e o técnico se completam e se adaptam um ao outro. Tal afirmação pode ser verificada não apenas quando se trata de infertilidade, mas também de questões referentes ao aborto ou, mesmo, à forma física dos corpos cada vez mais padronizados e iguais (Rosi BRAIDOTTI, 2001).

O corpo se transforma, assim, em um objeto de proliferação de discursos e de conhecimentos, de modos de normatividade que interessam simultaneamente a diferentes campos, com destaque para o político e o científico.

\section{Conclusões possíveis}

Ao refletir sobre como o tema da infertilidade foi tratado na Revista Pais \& Filhos, percebe-se que esse veículo de comunicação nunca foi neutro ou forneceu possibilidades diversas para mulheres e homens com dificuldades em ter filhos. Isso se confirma pelo fato de que a revista sempre articula como 'cura' ou superação do 'problema/defeito' de não ter filhos um saber construído no campo médico e difundido por diversos meios, dentre eles, a Pais \& Filhos. Dessa forma, para tal revista, o corpo sadio era fértil, e se a gravidez não ocorresse de forma espontânea, os vários especialistas deveriam ser consultados e ouvidos, sendo esse o 'fim' determinado para todas as mulheres.

Nessa perspectiva, a revista era uma peça sofisticada na maquinaria de produção de corpos educados, corpos dóceis.

As mulheres são instigadas, na revista, a um constante exercício de autodomínio, de vigilância sobre si para conseguir a gestação, ou seja, para 'vencer a infertilidade'. Em várias passagens, encontram-se afirmações do tipo: "É necessário se prestar atenção ao muco vaginal para se saber quando se está ovulando", ou então, "É necessário seguir todas as regras e procedimentos ditados pelos especialistas". Outra estratégia discursiva era a orientação "É necessário reconhecer o quanto antes a gestação no corpo" e, finalmente, "É necessário consultar um médico o quanto antes". ${ }^{3}$

Tais discursos acabam por legitimar o corpo feminino como sustentáculo do processo reprodutivo e os efeitos desse disciplinamento constituem uma tecnologia de poder que proporciona a emergência de uma nova consciência sobre o corpo. Assim, se produz nas

\footnotetext{
${ }^{3}$ Argumentos normativos retirados de diversas edições da Revista Pais \& Filhos (1968 a 2000).
} 
mulheres, a partir de seus corpos, um controle de sua condição, e mais, se reforça a ideia de que existe uma "condição de mulher", que seria a experiência da maternidade.

Estar grávida e ser mãe parecem ocupar uma posição de prestígio dentro do contexto da revista e, dessa forma, a infertilidade ou a esterilidade são apresentadas como fantasmas que amedrontam os casais - e as mulheres em especial.

Ao voltar o olhar para outros temas dentro da revista, como, por exemplo, a participação masculina no cuidado das crianças, percebe-se que a Pais \& Filhos modificou significativamente o discurso, pois, a partir da década de 1980, ocorreu uma incorporação da figura paterna em tais assuntos dentro da revista. Todavia, o mesmo não se verifica quando analisamos o tema da infertilidade. As modificações foram muito sutis, limitandose a mencionar que, caso a tecnologia reprodutiva não ajude, é possível encontrar outros caminhos de realização além da maternidade. Contudo, o uso da tecnologia reprodutiva é ainda bastante incentivado.

Desta forma, em se tratando de infertilidade e esterilidade, a revista manteve, durante todo o período estudado (1968 a 2000), o mesmo discurso, um discurso de limitação feminina pela ausência de maternidade, um discurso de 'cura' e de 'culpa', buscando encontrar razões que justificassem essa "falha da natureza". Tais razões poderiam vir da genética ou mesmo da vida cotidiana, como o estresse.

Mas para além de se encontrar razões e culpas, a revista se propunha a apresentar soluções para mulheres isoladas por seus "corpos imperfeitos", aproximando-as dos médicos especialistas na área de reprodução humana. Curar mulheres imperfeitas, essa era a lógica e o discurso da revista, no que tange à infertilidade, em consonância com o discurso médico consolidado desde o início do século XX.

$\mathrm{E}$, ao longo daquele século, foram construídos saberes, exercidos poderes e elaborados discursos vinculados ao medo, à culpa e à imperfeição das mulheres. As possibilidades para ser feliz ainda estão bastante limitadas pelos discursos normativos, pois a maternidade ainda é vista pelo senso comum como um destino, um dever, e poucas vezes é considerada como uma das muitas escolhas possíveis das mulheres.

Todavia, cabe ressaltar que diferentes pesquisas nas ciências humanas e sociais apontam para um rompimento, ao menos parcial, com esse discurso normativo sobre mães, ausência de maternidade e infertilidade que a revista procurou consolidar (Elisabeth BADINTER [1985, 201 1]; Aminatta FORNA [1999]; Lucila SCAVONE [2001]; Jeanne SAFER [1997]; Fabíola ROHDEN [2003]; Luci Helena Beraldo MANSUR [2003]; Sharon HAYS [1998]; Georgiane Garabely Heil VÁZQUEZ [2015; 2016]).

Elas, as mulheres sem filhos, fogem, felizmente, aos padrões traçados para estereotipá-las. Maternidade, enfim, não é destino.

\section{Referências}

BADINTER, Elisabeth. Um amor conquistado: o Mito do Amor Materno. Rio de Janeiro: Nova Fronteira, 1985.

. O Conflito: a mulher e a mãe. Rio de Janeiro: Record, 2011.

BRAIDOTII, Rosi. Sujetos nómades: Corporizacion y diferencia sexual em La teoria feminista contemporânea. Buenos Aires: Paidós, 2001.

BUTLER, Judith. "Corpos que pesam: sobre os limites discursivos do sexo". In: LOURO, Guacira Lopes. O copo educado: pedagogia da sexualidade. 2.ed. Belo Horizonte: Autêntica, 2000. p. 110-126.

. Cuerpos que importam: sobre los limites materiales y discursivos del "sexo". Buenos Aires: Paídos, 2002.

12 Revista Estudos Feministas, Florianópolis, 26(1): e44155 
CADA vez mais casos de esterilidade têm um final feliz. Revista Pais \& Filhos, n. 1, p. 108, set. 1978.

DOUTOR, posso ser mãe? Revista Pais \& Filhos, Rio de Janeiro, n. 9, p. 89-91, mai. 1972.

ELES venceram a esterilidade. Revista Pais \& Filhos, Rio de Janeiro, n. 9, mai. 1972.

ENGEL, Magali. "Psiquiatria e feminilidade". In: DEL PRIORE, Mary. História das Mulheres no Brasil (Org.). São Paulo: Contexto, 1997. p. 322- 361.

ESTERILIDADE: um mal que pode ser inteiramente curado. Revista Pais \& Filhos, Rio de Janeiro, n. 1, p. 47, set. 1973.

FORNA, Aminatta. Mãe de todos os mitos: como a sociedade modela e reprime as mães. Rio de Janeiro: Ediouro, 1999.

HARAWAY, Donna; KUNZRU, Hari; TADEU, Tomaz (Orgs.). Antropologia do ciborgue: As vertigens do pós-humano. Belo Horizonte: Autêntica, 2000.

HAYS, Sharon. Contradições culturais da maternidade. Rio de Janeiro: Gryphus, 1998.

HOMEM também é estéril. Revista Pais \& Filhos, Rio de Janeiro, n. 6, p. 28, 30, fev. 1969.

NOVAS descobertas na cura da esterilidade. Revista Pais \& Filhos, Rio de Janeiro, n. 5, p. 18, jan. 1973.

LUCA, Tania Regina de. "História dos, nos e por meio de periódicos". In: PINSKY, Carla Bassanezi et al. (Orgs.). Fontes Históricas. São Paulo: Contexto, 2005. p. 111-153.

MANSUR, Luci Helena Beraldo. Sem filhos: a mulher singular no plural. São Paulo: Casa do Psicólogo, 2003.

MARTINS, Ana Paula Vosne. A medicina da mulher: visões do corpo feminino na constituição da obstetrícia e da ginecologia do século XIX. 2000. Tese (Doutorado em História) UNICAMP, Campinas, SP, Brasil.

PAIS \& FILHOS. Rio de Janeiro, n. 7, p. 40, mar. 1976. . Rio de Janeiro, n. 11, p. 114, jul. 1985.

RAGO, Margareth. "Dizer sim à existência". In: __ _ ; VEIGA-NETO, Alfredo (Orgs.). Para uma vida não fascista. Belo Horizonte: Autêntica, 2009. p. 253-268.

ROHDEN, Fabíola. A arte de enganar a natureza. Contracepção, aborto e infanticídio no início do século XX. Rio de Janeiro: Fiocruz, 2003.

SAFER, Jeanne. Além da maternidade. Optando por uma vida sem filhos. São Paulo: Mandarim, 1997.

SCAVONE, Lucila. "A maternidade e o feminismo: diálogo com as Ciência Sociais". Cadernos Pagu, São Paulo, n. 16, p. 137-150, jan./jul. 2001.

SCHWENGBER, Maria Simone. Donas de Si?: educação de corpos grávidos no contexto da Pais e Filhos. 2006. Tese (Doutorado em Educação) - Universidade Federal do Rio Grande do Sul, Porto Alegre, RS, Brasil.

. "Distinções e articulações entre corpos femininos e corpos grávidos na Pais \& Filhos". In: MARTINS, Ana Paula Vosne (Org.). História: Questões \& Debates, Curitiba, UFPR, n. 47, p. 123-138, jul./dez. 2007. (Dossiê Parto e Maternidade)

TAMANINI, Marlene. Novas Tecnologias Reprodutivas à luz da bioética e das teorias de gênero: casais e médicos no Sul do Brasil. 2003. Tese (Doutorado Interdisciplinar em Ciências Humanas) - Centro de Filosofia e Ciências Humanas, Programa de PósGraduação em Ciências Humanas, Universidade Federal de Santa Catarina, Florianópolis, SC, Brasil.

VASECTOMIA: a esterilidade ao alcance do homem. Revista Pais \& Filhos, Rio de Janeiro, n. 5, mar. 1977.

VÁZQUEZ, Georgiane Garabely Heil. Da mãe que não fui. A experiência da ausência de maternidade ao longo do século XX. 2015. Tese (Doutorado em História) - Universidade Federal do Paraná, Curitiba, PR, Brasil. 
"Memórias de uma ausência: mulheres sem filhos e suas narrativas sobre maternidade no Paraná do século XX". Revista de História Regional, v. 21, n. 2, p. 338-363, 2016.

[Recebido em 12/04/2016, reapresentado em $21 / 12 / 2016$ e aprovado em 22/05/2017]

Imperfections on Paper: Infertility in the Pages of the Revista Pais \& Filhos

Abstract: This research was aimed at the analysis of sterility / infertility in the second half of the Twentieth Century in Brazil, through a documentary analysis of the Revista Pais \& Filhos. The central themes debated were the narratives constructed by the magazine about the difficulty or impossibility of having a child. The interest was related to the articulation between the medical knowledge and the speeches presented in the Pais \& Filhos, when the subject of the infertility was approached. The reflections of Butler (2000; 2002), Braidotti (2001), Haraway, Kunzru and Tadeu (2000), among others, were used as theoretical bases. In general, one can observe that the magazine constructed narrative strategies that turned infertile women into sick people. Gestation and the exercise of motherhood were widely valued by the magazine.

Keywords: Infertility; Motherhood; Gender; Parents \& Children Magazine

Georgiane Garabely Heil Vázquez (profgeorgiane@hotmail.com) é historiadora feminista. Professora do Departamento de História e professora colaboradora no Programa de Pós-Graduação em História - Mestrado - da Universidade Estadual de Ponta Grossa (UEPG), Paraná. É doutora e mestra em História pela Universidade Federal do Paraná com pesquisas voltadas para a área de Estudos de Gênero. Atualmente é coordenadora Estadual do GT de Estudos de Gênero da Associação Nacional de História, seção Paraná (ANPUH/PR) e membro coordenador do Laboratório de Estudos de Gênero, Diversidade, Infância e Subjetividades (LAGEDIS) da Universidade Estadual de Ponta Grossa. Pesquisadora vinculada ao grupo "História da Assistência à Saúde" (COC-FIOCRUZ) e membro do Núcleo de Estudos de Gênero (NEG) da Universidade Federal do Paraná. Desenvolve pesquisas sobre Estudos de Gênero, feminismos, medicina e cultura, história da medicina, maternidade e memórias.

14 Revista Estudos Feministas, Florianópolis, 26(1): e44155 